\title{
PROLAPSO URETRAL ENCARCERADO. A PROPÓSITO DE UN CASO CLÍNICO
}

Mario Jorge Soares, Ana Covita, Tiago Neves, Pedro Monteiro, Artur Canhoto, Rui Nogueira, José Luis Barreto, José Carlos Mendonça, Manuela Maya y Helder Monteiro.

Servicio de Urologia y Servicio de Anatomia Patológica'. Hospital Egaz Moniz. Lisboa. Portugal.

Resumen.- OBJETIVO: Presentar un caso clínico de prolapso de la mucosa uretral encarcerado.

MÉTODOS/RESULTADOS: Paciente del sexo femenino de 62 años de edad. Acude al Servicio de urgencias por masa vaginal sangrante acompañada de dolor, localizada en el introioto vaginal y disuria. Después del diagnóstico de prolapso de la mucosa uretral encarcerado, se sometió a exéresis quirúrgica del mismo. El examen histológico reveló uretra con proliferación vascular de tipo angiomatoso con trombosis y recanalización focal (Masson) e inclusión de raros fascículos de fibras musculares. El postoperatorio recorre sin incidencias, no recurrencias o problemas miccionales.

CONCLUSIÓN: Para el tratamiento del prolapso uretral encarcerado, la exéresis quirúrgica es el "gold stardard".

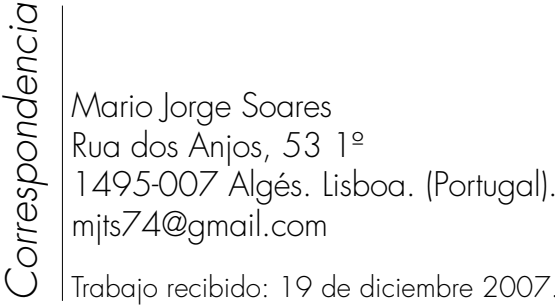


Palabras clave: Prolapso mucosa uretral. Prolapso encarcerado.

Summary.- OBIECTIVE: We report a case of strangulated urethral prolapse.

METHOD/RESULTS: A 62 year old female patient presents to the emergency department with complaints of a bleeding vaginal mass, pain referred to the vaginal introitus and dysu-ria. After being diagnosed with a strangulated urethral pro-lapse, surgical excision of the prolapsed urethra was performed. Pathologically, vascular proliferation of the angioma-tous type with thrombosis and focal recanalization(Masson) and inclusion of rare muscular fibers were recognized. Her postoperative course was uneventful, without any recurrence or abnormal micturition.

CONCLUSION: For the treatment of strangulated urethral prolapse, surgical excision has been widely applied with successful results.

Keywords: Urethral mucosa prolapse. Strangulated prolapse.

\section{CASO CLÍNICO}

Paciente del sexo femenino de 62 años que acude al servicio de urgencias por dolor intensa localizada en el introito vaginal, sangrado vaginal y disuria. Al examen objetivo se observa masa circular en forma de "donut", edemasiada, eritematosa, friable y con necrosis, sangrado al tacto vaginal, aproximadamente de $3 \mathrm{~cm}$ de diámetro y situada ventralmente en el introito vaginal. Examen con espéculo vaginal muestra ausencia de envolvimiento vaginal. Para observar la relación de la masa con el meato uretral se realiza el cateterismo vesical a través de la depresión central de la tumefacción. La presencia del "meato" uretral en posición central establece el diagnóstico de prolapso uretral encarcerado.

Se realiza exéresis del prolapso, con sutura de la mucosa uretral residual a la mucosa vaginal. La sonda vesical se retiró al quinto dia postoperatorio. Un mes después de la cirugía, la paciente niega disfunción miccional y no presenta estenosis del meato uretral.

El examen anatomo-patológico de la pieza quirúrgica reveló uretra con proliferación vascular de tipo angiomatoso con trombosis y recanalización focal (Masson) e inclusión de raros fascículos de fibras musculares.

\section{DISCUSIÓN}

El prolapso uretral es la eversión circular de la mucosa, con protusión de ésta por el meato uretral. Aparece como una tumefacción eritematosa y carnosa ventralmente en el introito vaginal.

Tiene una distribución etaria bimodal, apareciendo en niñas prepúberes y mujeres postmenopaúsicas. De las series de pacientes presentadas en la literatura, se constata entre éstos dos grupos un patrón racial y manifestaciones clínicas distintas. En la edad prepúbere, las niñas son sobretodo de raza negra y habitualmente no tienen dolor o problemas urinarios, acudiendo al médico por el sangrado vaginal. Las mujeres postmenopaúsicas son predominantemente de raza caucasiana y habitualmente tienen dolor y problemas miccionales. Éstas presentan frecuentemente síntomas de encarceramiento debido a obstrucción venosa: dolor intenso y problemas miccionales como polaquiuria, disuria y retención de orina. En caso de trombosis y necrosis, dolor y sangrado uretral serán los síntomas más frecuentes.

El diagnóstico es clínico en ambos grupos. Se presenta como una masa eritematosa, carnosa y friable, situada ventralmente en el introito vaginal. El cateterismo vesical a través de un orificio localizado en el centro de la masa hace el diagnóstico diferencial con la carúncula uretral, donde el orificio está situado encima de la masa. Para la exclusión de enfermedad neoplásica y el ureterocele ectópico prolapsado (en el caso de prolapso parcial), algunos autores recomiendan la realización de urografía intravenosa y cistoscopia. La masa extirpada se debe enviar para estudio anatomo-patológico.

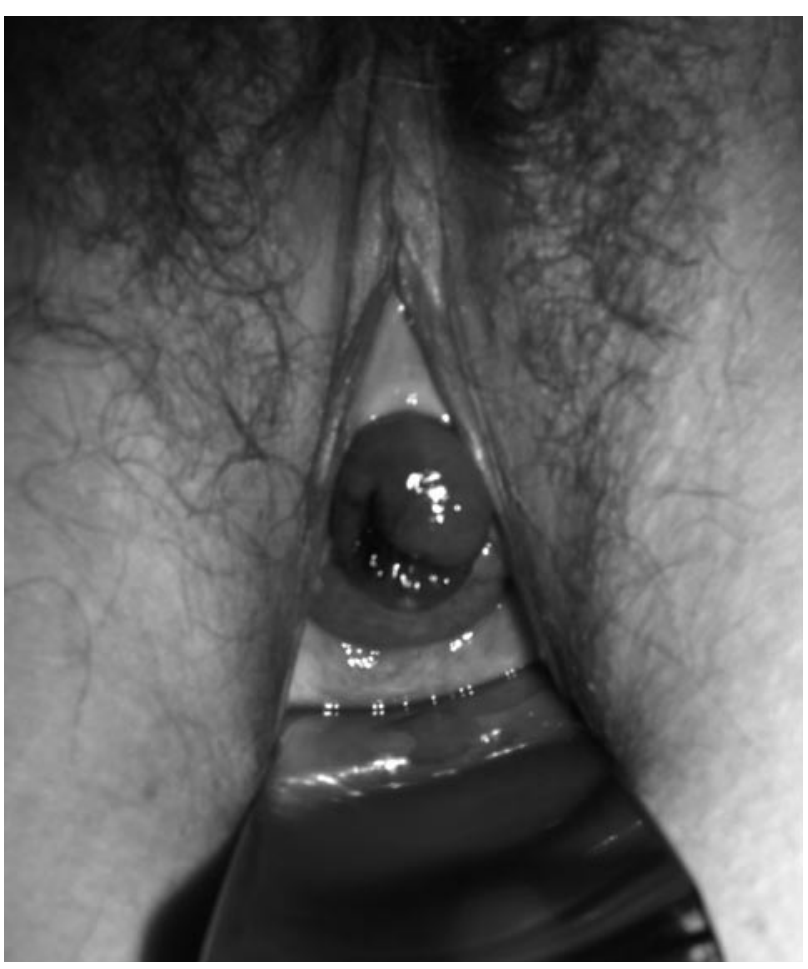

FIGURA 1. Prolapso uretral encarcerado. 


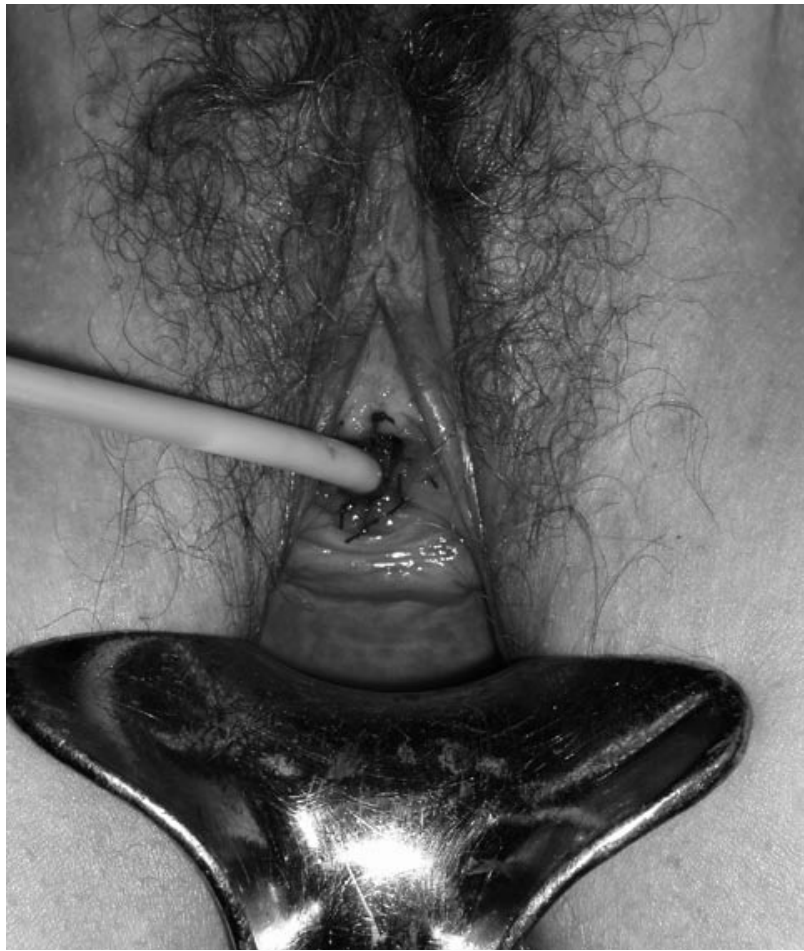

FIGURA 2. Posterior exéresis y anastomosis de la mucosa uretral a la mucosa vestibular.

La etiología y fisiopatología son desconocidas. La deficiencia estrogénica puede tener un papel importante. Una teoría presentada asocia episodios de aumento de presión intraabdominal provoca la deficiente adherencia entre la capa de músculo liso longitudinal interna y la capa de músculo liso circular externa.

\section{CONCLUSIONES}

El tratamiento puede ser médico o quirúrgico. Los tratamientos médicos utilizados han sido baños de asiento, aplicación tópica de estrógenos y la reducción manual, siempre y cuando la mucosa sea viable. En el caso de prolapso recurrente y sintomático, o de prolapso encarcerado, la exéresis quirúrgica simple está asociada a baja morbilidad y elevado éxito.

\section{BIBLIOGRAFIA y LECTURAS RECOMENDADAS (*lectura de interés $y$ ** lectura fundamental)}

**1. GOLOMB, J.; MERIMSKY, E.; BRAF, Z.: "Strangulated prolapse of the uretra in the elderly female". Int. J. Gynaecology. Obstet., 23: 61, 1985.

*2. SHURTLEFF, B.T.; BARONE, J.G.: "Urethral prolapse: Four quadrant excisional technique". J. Pediatr. Adolesc. Gynecol., 15: 209, 2002.
*3. KLEINJAN, J.H.; VOS, P.: "Strangulated urethral prolapse". Urology, 47: 599, 1996.

4. VALERIE, E.; GILCHRIST, B.F.; FRISCHER, J. y cols.: "Diagnosis and treatment of urethral prolapse in children”. Urology, 54: 1082, 1999. 